\title{
THE
}

\section{A randomized comparative effectiveness study of Healthy Directions 2-A multiple risk behavior intervention for primary care}

\author{
Karen M. Emmons \\ Elaine Puleo \\ Mary L. Greaney \\ University of Rhode Island, mgreaney@uri.edu \\ Matthew W. Gillman \\ Gary G. Bennett \\ Follow this and additional works at: https://digitalcommons.uri.edu/kinesiology_facpubs \\ Phis is \\ Creative Commons License \\ (c) (i) (9)
}

This work is licensed under a Creative Commons Attribution-Noncommercial-No Derivative Works 4.0 License.

\section{Citation/Publisher Attribution}

Emmons, K. M., Puleo, E., Greaney, M. L., Gillman, M. W., Bennett, G. G., Haines, J., Sprunck-Harrild, K., \& Viswanath, K. (2014). A randomized comparative effectiveness study of Healthy Directions 2-A multiple risk behavior intervention for primary care. Preventive Medicine, 64, 96-102. doi: 10.1016/ j.ypmed.2014.03.011 Available at: https://doi.org/10.1016/j.ypmed.2014.03.011 accepted for inclusion in Kinesiology Faculty Publications by an authorized administrator of DigitalCommons@URI. For more information, please contact digitalcommons-group@uri.edu. 
Authors

Karen M. Emmons, Elaine Puleo, Mary L. Greaney, Matthew W. Gillman, Gary G. Bennett, Jess Haines, Kim Sprunck-Harrild, and K. Viswanath 


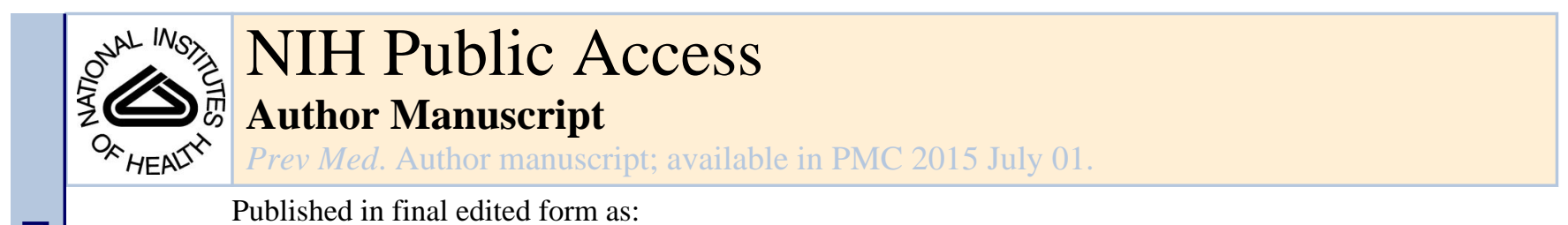

Published in final edited form as:

Prev Med. 2014 July ; 64: 96-102. doi:10.1016/j.ypmed.2014.03.011.

\title{
A Randomized Comparative Effectiveness Study of Healthy Directions 2-A Multiple Risk Behavior Intervention for Primary Care
}

\author{
Karen M. Emmons, Elaine Puleo, Mary L. Greaney, Matthew W. Gillman, Gary G. Bennett, \\ Jess Haines, Kim Sprunck-Harrild, and Vish Viswanath
}

\section{Abstract}

Objective-To evaluate the effectiveness of the Healthy Directions 2 (HD2) intervention in the primary care setting.

Methods-HD2 was a cluster randomized trial (conducted 3/09 - 11/11). Primary sampling unit was provider $(n=33)$, with secondary sampling of patients within provider $(n=2,440)$. Study arms included: 1) usual care (UC); 2) HD2-- a patient self-guided intervention targeting 5 risk behaviors; or 3) HD2 plus 2 brief telephone coaching calls (HD2+CC). The outcome measure was proportion of participants with a lower multiple risk behavior score (MRB) by follow-up.

Results-At baseline, only 4\% of participants met all behavioral recommendations. Both HD2 and $\mathrm{HD} 2+\mathrm{CC}$ led to improvements in MRB score, relative to UC, with no differences between the two HD2 conditions. Twenty-eight percent of UC participants had improved MRB scores at 6 mo., vs. $39 \%$ and $43 \%$ in HD2 and HD2+CC respectively (p's $\leq 001$ ); results were similar at 18 mo. $(\mathrm{p} \leq 05)$. The incremental cost of one risk factor reduction in MRB score was \$319 in HD2 and $\$ 440$ for HD2+CC.

Conclusions-Self-guided and coached intervention conditions had equivalent levels of effect in reducing multiple chronic disease risk factors, were relatively low cost, and thus are potentially useful for routine implementation in similar health settings.

\section{INTRODUCTION}

A large percentage of health care costs are a function of the coexistence of multiple chronic diseases (Tinetti et al. 2012). One in four of all US adults have multimorbidities, which accounts for $60 \%$ of US health care spending. The number of Americans living with multimorbidities is increasing at a faster rate than expected (Anderson G 2010). The vast

\footnotetext{
(C) 2014 Elsevier Inc. All rights reserved.

Address communications and reprint requests to: Karen M. Emmons, Ph.D., Kaiser Foundation Research Institute, 1800 Harrison Avenue, Oakland CA 94612 phone: (510)625-4724; Karen.m.emmons@kp.org.

Conflict of Interest: None of the authors have conflict of interest to report.

Clinical Trial Registration: NCT01415492, "Multiple Risk Behavior Intervention in Health Care Settings (HD2)".

Publisher's Disclaimer: This is a PDF file of an unedited manuscript that has been accepted for publication. As a service to our customers we are providing this early version of the manuscript. The manuscript will undergo copyediting, typesetting, and review of the resulting proof before it is published in its final citable form. Please note that during the production process errors may be discovered which could affect the content, and all legal disclaimers that apply to the journal pertain.
} 
majority of older adults (73\%) have multiple chronic conditions, as do a significant and growing number of people under 65 years of age (Anderson G 2010; Tinetti et al. 2012; Weiss et al. 2007).

The increasing prevalence of multimorbidities is at least in part a function of the health behavior profile of US adults, most of whom have multiple risk factors for chronic disease. Seventy-seven percent of US adults do not meet the dietary guidelines, $49 \%$ do not meet recommended physical activity levels, and $18 \%$ are current smokers (CDC 2012). Poor health behaviors tend to co-occur (Blair SN et al. 1985; Emmons et al. 1994; Gillman et al. 2001; Jeffery et al. 1993; Pirie et al. 1992; Simons-Morton et al. 1991; Troost et al. 2012; Unger 1996), and prevalence has not changed much in the past two decades. One reason for this may be that it is inefficient to target the behavioral risk factors for multimorbidities as separate entities, especially when similar behavior change principles apply and behaviors are interrelated.

Only a few randomized control trials have intervened on multiple risk behaviors (MRB) simultaneously (Elmer et al. 2006; Emmons et al. 2005a; Marcus et al. 1999; Resnicow et al. 2005; Spring et al. 2010; Spring et al. 2012b), with very limited emphasis either on multiple risk outcomes or on population level effects. These have largely been efficacy studies that include more extensive interventions than are possible in most primary care settings (Emmons et al. 2005b). To facilitate translation to practice, it is important to develop effective interventions that are both low in cost and have high reach. Development of sustainable interventions for primary care is particularly important given the current focus within health care reform on prevention. It is critical that we study these interventions in real-world primary care settings, and learn how to package them so that they can be sustained by health care systems.

This paper reports on the results of the Healthy Directions 2 trial (HD2), a cluster randomized control trial to evaluate the comparative effectiveness of two versions of a MRB intervention conducted in the primary care setting. The intervention targeted physical activity, fruit and vegetable intake, red meat consumption, multi-vitamin use, and smoking cessation. These risk behaviors are associated with the leading causes of chronic disease morbidity and mortality (Hung et al. 2004; Pan et al. 2012; U.S. Department of Agriculture and U.S. Department of Health and Human Services 2010; Warburton DE et al. 2008; Warburton et al. 2006), and reflect behaviors that were a priority in the participating health care system. This study compares the impact of self-guided vs. coached interventions on reduction of these risk factors simultaneously. The primary comparison evaluated the outcomes of usual care (UC) compared with: (1) the self-guided Healthy Directions 2 (HD2) intervention, delivered via web or print (modality selected by the patient); and (2) the HD2 intervention plus two brief coaching calls designed to activate use of the intervention materials $(\mathrm{HD} 2+\mathrm{CC})$. Cost-effectiveness of the interventions was a secondary outcome. 


\section{METHODS}

\section{Study Design}

HD2 was a cluster randomized control comparative effectiveness trial conducted in internal medicine practices of two urban health centers of a healthcare delivery system in metropolitan Boston (Greaney ML et al. In Press). Randomization to three study arms occurred at the level of primary care provider ( $n=33)$ : 1) UC; 2) HD2 or 3) HD2+CC (see CONSORT diagram, Figure 1). HD2 and HD2+CC addressed the 5 target behaviors simultaneously. This study was conducted between March, 2009 and November, 2011. The study was approved by the Institutional Review Board at Harvard Pilgrim Health Care.

The primary sampling unit was the primary care physician (PCP) and there were 3 randomization arms. Sample size was determined using methods for studies with randomization by cluster (Donner et al. 1981), based on results from our previous trial. We estimated that the within PCP standard deviation would be .91, and the within subject correlation would be .5, yielding an estimated variance of the difference of 1.66 . We have demonstrated very low values of within-center correlation, and thus estimated the withinPCP correlation (r) to be .01. With a final projected $\mathrm{N}$ of 60 subjects per PCP and $10 \mathrm{PCPs}$ in the usual care condition, and 90 subjects per PCP and 10 PCPs in the two intervention conditions, there was $80 \%$ power to detect a significant difference in the mean change in number of risk factors (2-sided) between any two of the conditions of 0.28 at the $5 \%$ significance level. The random allocation sequence was generated and overseen by the study biostatistician.

\section{Participants}

Patients were eligible if they: 1) were 18+ years of age; 2) could read English; 3) had not received a diagnosis of dementia, blindness, neurodegenerative or psychiatric illness (previous 5 years); and 4) were not undergoing cancer treatment (previous 12 months). Potentially eligible patients were identified via the electronic medical record (EMR). We sent those who had a scheduled well-care visit or chronic disease management appointment an introduction letter with "opt out" information. Upon check-in, the clinic staff introduced the patient to study staff, who confirmed eligibility and obtained informed consent. The study was presented as an effort to learn how best to help health care providers support patients to live a healthy lifestyle. Participants then completed the baseline survey. About half $(52 \%, \mathrm{n}=2,440)$ of the patients who were approached enrolled in the study and received a $\$ 5$ gift card after the baseline survey. We collected follow-up data via a telephone survey at the end of the 6-month intervention and at 18 months; completers received $\$ 5$ and $\$ 20$ gift cards, respectively. The data collection team was blind to condition assignment. The retention rates were $69 \%$ at 6 months and $75 \%$ at 18 -months. We received IRB approval to pull de-identified aggregate data on non-enrollees.

\section{Intervention Conditions}

Usual Care (UC) - UC participants received the current standard of care offered by their individual provider; the participating practices did not have a standard practice protocol for the target behaviors, with the exception of a referral service for the state tobacco control 
program. Thus, provision of standard materials ensured that all UC participants received at least basic messages about the target risk factors. Four basic health promotion brochures, published by the American Cancer Society, were provided to the UC condition participants: Living Smart; Choices for Good Health; Cooking Smart; and Take Control of Your Health. A smoking cessation brochure, from the state of Massachusetts' Tobacco Control Program, was also provided.

HD2 Intervention (HD2)-The intervention focused on influences at the individual, interpersonal, and community levels (McLeroy et al. 1988; Sorensen et al. 2003) that could motivate and maintain behavior change, and be sustainable. Components included: 1) provider endorsement using a brief script ( $<30$ seconds); 2 ) intervention materials via web or print (patient choice) which included national recommendations in the 5 behavioral areas: quit smoking if a smoker, eat $\leq 3$ servings of red meat per week, eat 5-9 servings of fruits and vegetables daily, get at least 30 minutes of moderate physical activity 5 or more days per week and/or walk at least 10,000 steps per day, and take a daily multi-vitamin; tracking of each health behavior was available on a daily basis; tips and resources to meet the recommendations were provided; 3 ) two tailored feedback reports (post-baseline and 6months) focused on behaviors for which participants were/were not meeting guidelines; 4) materials for participants' social network to support their behavior change efforts; and 5) links to key community-based resources. Participants in the HD2 arms received a bottle of multivitamins and a pedometer.

The materials emphasized changing multiple behaviors simultaneously, and focused on behavioral tracking and action planning. The website had planning and tracking components for daily reporting on the target behaviors and provided feedback on progress over time. The print materials had a similar mechanism designed for a paper format. Action planning was introduced in the "Welcome" booklet, where participants were encouraged to use the "Plan My Changes" booklet to formulate reasonable and specific health goals and think about how to reach them. Barrier reduction tips were provided. Participants chose the behaviors they wished to change and were able to document specific ways in which to achieve the goal(s). Participants were given two "Plan My Changes" booklets, one to be used at the beginning of the intervention, and one to be used 3 months later. Print participants were also given a "Track My Changes" booklet, which included printed log sheet that let them track their progress on a daily and weekly basis.

HD2 Intervention Plus Coaching (HD2+CC)—Participants in this arm received all of the HD2 components plus two brief coaching calls, at 2 and 6 weeks after enrollment. The Health Coaches were trained in the principles of brief motivational interviewing (Miller and Rollnick 1991). The calls were 5-10 minutes and focused on increasing engagement with the intervention, selecting achievable goals, and developing strategies to address barriers and meet selected goals.

\section{Primary Outcome Measure}

The primary outcome measure was the Multiple Risk Behavior Score (MRB), which ranged from 0 (met all behavioral recommendations) to 5 (met none of the recommendations). One 
point was given for each behavioral risk factor not met. Participants reported on all targeted behaviors and the results for each behavior were dichotomized as to whether a person did or did not meet recommended guidelines. Participants with incomplete data for one or more behaviors at baseline assessment were classified as not meeting those behavioral recommendations $(\mathrm{n}=61)$. Physical activity was assessed using the CDC's Behavioral Risk Factor Surveillance Survey (BRFSS) measure that evaluates moderate (brisk walking, biking or anything that causes small increases in breathing or heart rate) and vigorous activity (running, aerobics or anything else that causes large increases in breathing or heart rate) during a usual week (Estabrooks et al. 2008; Macera et al. 2001). Reported minutes of moderate and vigorous physical activity were summed into a total number of weekly minutes, and then dichotomized as to whether a person met the current recommendation of $150+$ minutes of moderate activity or $60+$ minutes of vigorous activity or the equivalent per week (U.S. Department of Health and Human Services 2008). Fruit and vegetable intake was assessed using the "5 A Day for Better Health" tool, a validated 7-item instrument covering different types of fruit and vegetable items consumed over the previous month (Serdula et al. 1993). Total daily servings were calculated (excluding fried potatoes and French fries), with 5+ servings/day being the daily recommended intake (U.S. Department of Agriculture and U.S. Department of Health and Human Services 2005). Red meat intake over the previous month was assessed with an abbreviated form of the semi-quantitative Food Frequency Questionnaire (Willett et al. 1985). Responses were recoded and summed to obtain total servings per week and then dichotomized, with $<3$ servings/week recommended (U.S. Department of Agriculture and U.S. Department of Health and Human Services 2005). Multi-vitamin intake was assessed by asking respondents how many days per week, on average, they took a multivitamin (Emmons et al. 2005a). Participants were classified as meeting the recommendation if they reported taking a multi-vitamin at least 6 days per week. Smoking was assessed using the BRFSS Tobacco Use module, which assesses lifetime and current smoking (past 7 days). Non-smokers were classified as meeting smoking guidelines.

We examined cost-effectiveness following Ritzwoller's methods (Ritzwoller et al. 2011). Although we collected costs related to both research requirements and intervention delivery, our cost analyses are restricted to those intervention-related costs needed to replicate the intervention. We collected cost data for all intervention activities, pro-rated to items needed to generate the intervention materials and staff salaries. We estimated minutes of time spent on different staff related activities and multiplied this by an hourly staff rate (including benefits) based on the staff member position conducting the activity. For the staff time spent during the delivery of the intervention, we considered 6 different types of activities: (a) database management (e.g., time spent tracking participants and study related data); (b) material preparation (e.g., time spent running algorithms to prepare materials such as the tailored feedback reports and collating materials); (c) mailing (e.g., time spent mailing incentives and study related materials); (d) health coaching activities; (e) general correspondence with study participants; and (f) other. We used invoices to document costs related to text and voice reminders, as well for costs of materials/supplies, mailing and printing costs, and incentives used for the three conditions. We did not include material development costs as our focus was on the health plan perspective of implementation once 
developed. We also did not include the costs of the usual care materials and distribution because we used free government sources for these materials, and many PCPs routinely distribute these types of materials. We did not include participant costs as it was not possible to accurately estimate participant time spent on this self-guided intervention.

\section{Data Analysis}

Data were collected using a cluster design with provider being the primary sampling unit (cluster) and patient as the secondary sampling unit; the sample was weighted proportional to the physician panel size in our analysis $(n=41,495)$. All outcome analyses were conducted using multiple imputation methods to account for missing data. Using SAS procedure MI we generated 10 datasets that multiply imputed the missing values. Once these 10 "complete" datasets were created, we used standard SAS programs (logistic regression, crosstabs etc.) on each. Then we used the procedure MIANALYZE to combine the results and generate valid statistical inference. To more accurately reflect true change over the course of the study, we controlled for baseline values of MRB. We used polytomous logistic regression modeling of change in MRB (categorical primary outcome: improved/stayed the same/ worsened), modeling the outcome on a priori chosen independent variables (demographics, intervention arm, etc.) along with the continuous MRB at baseline in an ANCOVA type model.

We calculated the cost per unit change in MRB at 18 months for each of the two interventions compared with control. Intervention costs were categorized as personnel costs, tangible incentives, printing and mailing costs, supplies and miscellaneous. In each of the two intervention groups, costs were then divided by the number of participants to establish a per person cost. We then calculated the difference in mean change in MRB between intervention and control. The incremental cost for a change in 1 risk factor was calculated as the per person cost divided by the difference in mean change for each intervention group.

\section{RESULTS}

\section{Participant Characteristics}

Participants were racially/ethnically diverse ( $45 \%$ non-white), $66 \%$ of the population were women and $63 \%$ were married or living with a partner (see Table 1). Only $4 \%$ of participants met all 5 behavioral recommendations at baseline, $17 \%$ met 4 recommendations, and about half met 2 or fewer recommendations.

To assess representativeness of the study sample, we compared the demographic characteristics of the study participants with the patients we contacted but who did not enroll (see Figure 1). Women were more likely to enroll than men, and African Americans/Blacks were less likely to enroll than those of other race/ethnicities. To assess selection bias, we compared participants lost to follow-up at 18 months to those we retained in the study. Study completers included a higher proportion of women, Whites and Hispanics (v. other racial/ethnic groups), those of normal or overweight (v. obesity), and those in the usual care condition. 


\section{Comparative Effectiveness of Self-Guided (HD2), Coached (HD2+CC) and Usual Care (UC) Interventions}

HD2 and HD2+CC both led to improvements in MRB score compared with UC; $28 \%$ of UC participants had improved MRB scores at 6 mo., vs. 39\% and 43\% in HD2 and HD2+CC respectively ( $\mathrm{p} \unlhd 0.001$ ), reflecting a 53\% relative improvement for the HD2+CC condition (see Figure 2). At 18 months, 31\% of UC participants had improved MRB scores, vs. 39\% in HD2 and 40\% in HD2+CC respectively (p $₫ 0.05$ ), reflecting a 26\% difference between UC and each of the two HD2 conditions. More participants in the UC condition (19\%) had a worse MRB score (i.e., increased the number of risk behaviors), compared with HD2 (13\%) or HD2+CC $(15 \%, \mathrm{p} \leq 05)$ at 18 -months. There were no differences in outcomes between the self-guided or coached versions of HD2 at either of the follow-up assessments.

In post-hoc subgroup stratified analyses we found similar effects in terms of MRB outcomes in males and females at 18-months (HD2: $\mathrm{f} \leq 05, \mathrm{~m} \mathrm{p} \leq .01$; HD2+CC: $\mathrm{f} \mathrm{p} \leq 02, \mathrm{~m} \mathrm{p} \leq 05$ vs. usual care). Similar effects also were found for whites and non-whites (HD2: whites $p \leq 01$, non-whites $\mathrm{p} \leq 01$ vs. usual care; HD2+CC: whites $\mathrm{p} \leq 05$, non-whites $\mathrm{p} \leq 03$ vs. usual care).

\section{Cost Effectiveness}

The average cost of the HD2 intervention was $\$ 55.84$ per participant (pp), and the HD2+CC cost was $\$ 67.55 / \mathrm{pp}$. The difference in mean change in MRB between HD2 and UC was 0.15 and between $\mathrm{HD} 2+\mathrm{CC}$ and Usual Care was 0.18 . Thus, dividing the cost by the difference in mean change, the incremental cost-effectiveness for a 1-unit improvement in the MRB score was $\$ 319$ for HD2, and $\$ 440$ for HD2+CC.

\section{DISCUSSION}

The HD2 intervention, with and without coaching calls, significantly improved the MRB score among a large and diverse population of primary care patients, reflecting between a $25 \%$ and 50\% improvement over usual care (18- and 6-month follow-ups, respectively). The study is one of the few conducted in the primary care setting to examine behavior change across multiple risk factors simultaneously. In addition, the study was designed to explicitly address two questions posed to us by the participating health care system, which was interested in low-cost, high-reach interventions that ultimately result in lower risk of chronic disease.

The first question was, "what is the added benefit of coaching over self-guided interventions?". In this population, phone-based coaching did not further improve outcomes over and above the self-guided formats of the intervention. However, both the self-guided and coached forms of HD2 led to similarly improved MRB outcomes over usual care.

A second question was "What are the associated costs and effects of the different interventions?". Over a 6-month period, the HD2 and HD2+CC arms cost \$319 and \$440 respectively for 1-point improvement in the $0-5 \mathrm{MRB}$ score. It may be useful to contrast the cost of HD2, which targets behaviors that can significantly reduce risk of hypertension and elevated lipids, with that of a 6-month supply of Crestor, which costs approximately $\$ 1,056$ (Consumer Reports Health 2012). Long-term medical treatment of chronic diseases 
associated with the target risk behaviors are extremely costly for the health care system as well as for patients. No studies in the literature provide cost-effectiveness analyses for multiple risk behavior change among general primary care populations. A previous multiple behavior intervention, Project Prevent, conducted with patients who were at risk for colon cancer, included a cost analysis (Emmons, McBride, et al., 2005). Patients received the intervention shortly following diagnosis and removal of adenomatous colon polyps. The net per-person cost of the PREVENT intervention (delivered by phone and mail) over UC was $\$ 45.53$, or $\$ 228$ per unit change in multiple behavior score. A telephone-delivered intervention for physical activity and diet among patients with existing chronic disease had intervention costs between $\$ 410-\$ 570$ per participant (Graves et al. 2009). Ritzwoller et al., conducted cost analyses for a multiple behavior intervention study for Latinas with diabetes, ¡Viva Bien! (Ritzwoller et al. 2011). The intervention cost $\$ 7,723$ in both per unit reduction in hemoglobin A1c and per unit reduction in body mass index, although cost per unit behavior change was not provided, making comparisons to the present study difficult. In a web-based intervention for fruit and vegetable consumption, Sukhanova and colleagues (Sukhanova et al. 2009) found that the cost per additional serving of fruit and vegetables per day was $\$ 35$ in a tailored website condition, and $\$ 61$ for the tailored condition plus personalized counseling via email. HD2 targeted multiple risk factors and focused on reduction of the number of risk factors rather than movement within risk factors on a continuous scale (e.g. meet fruit and vegetable recommendation by eating 5 servings/day, vs. increase intake from 0 to 1 serving/day).

Together, the answers to these two questions suggest that a self-guided intervention like HD2 can improve chronic disease risk behaviors in a real-world setting at reasonable cost. Of note, this study demonstrates little added impact of brief coaching over the self-guided HD2 arm. We tried to address concerns in the literature about the cost and difficulty sustaining telephone counseling, and thus tested very brief phone coaching that was designed to activate participants to use the other intervention strategies. The added cost of the two coaching calls was modest (\$11.71), but did not yield significantly improved outcomes over HD2 alone. Thus, our findings suggest that if phone coaching is to be used, a more comprehensive version may be needed to add benefits over self-guided intervention elements. The costs of the self-guided HD2 intervention could be further reduced by utilizing an established delivery platform, such as an EMR, but the costs of coaching would be static. These findings are particularly important when considering prevention of chronic disease by reducing risk behaviors, compared with chronic disease management. Spring (Spring et al. 2012b) addressed cost concerns by evaluating a remote coaching intervention, delivered via mobile technologies, in combination with financial incentives for behavioral tracking among 204 adult volunteers. Significant improvements were found in fruit and vegetable intake and sedentary behavior. Further research is needed to identify strategies for enabling widespread use of evidence-based self-guided and mobile interventions in primary care settings.

There have been several calls to enhance the effectiveness of brief interventions in the health care setting and to boost their sustainability (Coups EJ et al. 2004; Ockene et al. 2000; Orleans 2004; Prochaska et al. 2010; Spring et al. 2012a); (Glasgow et al. 2002; Glasgow et 
al. 2001; Klesges et al. 2005). Tunis and colleagues (Tunis et al. 2003) argue that intervention studies should include realistic alternative treatment comparisons. HD2 was designed specifically to simulate real world conditions for participant enrollment and intervention delivery, and to explore the impact of different intervention modalities. One factor in HD2 that may have enhanced its success was allowing participants to select whether they received the intervention via print materials or a website, which may enhance engagement and satisfaction. In addition, the intervention addressed all five risk behaviors, which may have facilitated choice and engagement, as well as increasing applicability to a broad population. Fidelity to the intervention is another important consideration, and one which will be explored in subsequent analyses.

Study limitations should be noted. The 52\% enrollment rate is not as high as in some efficacy studies. However, it is higher than in many similar trials conducted within health care settings (e.g. $2 \%$ for a web-based multiple risk behavior intervention in primary care (Dickinson et al. 2013); 28\% for a primary care intervention focused on weight loss and physical activity (Hardcastle et al. 2013)). In the context of a real world comparative effectiveness study, this gives similar health care systems a realistic view of the likely intervention impact. This real world approach is reflected in the use of a modest incentive at enrollment ( $\$ 5$ for completion of baseline survey), and the fact that we approached patients only once to enroll. The response rate to the 18-month follow-up assessment was $75 \%$. Given the practice-based nature of this study, and when compared with similar studies, this rate of retention is adequate. Outcome analyses incorporated best practice approaches to handling missing data. All outcomes were self-reported, as is typical of large populationlevel studies. The MRB score was collected via two forms of administration (paper and phone interview), which resulted from efforts to implement the study in a generalizable fashion while simultaneously maximizing follow-up rates. However, in neither case was the data collected by an in-person interviewer, and thus it is likely that the measurement bias would be minimized. Finally, our MRB score does not reflect weighting of risk factors in terms of health effects or stage of readiness to change, as it is difficult to do so across a wide spectrum of potential chronic disease outcomes in a meaningful way.

Study strengths include a large and diverse sample, drawn from the patient panels of 33 physicians, and analysis appropriate to a cluster-randomized design. In addition, we developed the study specifically to address issues facing health care administrators who are trying to determine how to best design behavior change interventions for their populations that have increasing multiple risk behaviors and multimorbidities.

We conducted HD2 within the context of every day primary care, in which patients present with a range of risk factors. Thus, our findings contribute to practice-based evidence regarding implementation decisions in practice settings (Glasgow et al. 2006; Green 2006, 2008; Institute of Medicine 2001). This study demonstrated that a self-guided intervention, delivered in the primary care setting via multiple and flexible formats, can lead to improvements in multiple risk behaviors at modest cost. Integrating interventions like HD2 into the primary care setting will give health care providers practical and effective tools for stemming the tide of multimorbidities. 


\section{Acknowledgments}

We thank Harvard Vanguard Medical Associates for the opportunity to conduct our research in their clinical sites. The authors would also like to acknowledge Martha Zorn for her work on the data management and Nancy Klockson for participation in the manuscript preparation. This work was funded by NIH grants R01 CA123228 and K05 CA124415 (Emmons, PI) and K24 HL068041 (Gillman, PI).

\section{References}

Anderson, G. Chronic care: making the case for ongoing care. Robert Wood Johnson Foundation; Princeton, NJ: 2010. http://www.rwjf.org/files/research/50968chronic.care.chartbook.pdf [Accessed August 2012]

Blair SN, Jacobs DRJ, KEP. Relationships between exercise or physical activity and other health behaviors. Public Health Rep. 1985; 100:172-180. [PubMed: 3920715]

CDC. [Accessed Aug 18, 2012] Prevalence and trends data, BRFSS. 2012. http://apps.nccd.cdc.gov/ BRFSS

Consumer Reports Health. Best Buy Drugs, Evaluation statin drugs to treat: High cholesterol and heart disease comparing effectiveness, safety, and price. 2012. http://www.consumerreports.org/health/ resources/pdf/best-buy-drugs/StatinsUpdate-FINAL.pdf

Coups EJ, Gaba A, Orleans CT. Physician screening for multiple behavioral health risk factors. American journal of preventive medicine. 2004; 27:34-41. [PubMed: 15275672]

Dickinson WP, Glasgow RE, Fisher L, Dickinson LM, Christensen SM, Estabrooks PA, Miller BF. Use of a website to accomplish health behavior change: if you build it, will they come? And will it work if they do? Journal of the American Board of Family Medicine : JABFM. 2013; 26:168-176. [PubMed: 23471930]

Donner A, Birkett N, Buck C. Randomization by cluster. Sample size requirements and analysis. American journal of epidemiology. 1981; 114:906-914. [PubMed: 7315838]

Elmer PJ, Obarzanek E, Vollmer WM, Simons-Morton D, Stevens VJ, Young DR, Lin PH, Champagne C, Harsha DW, et al. Effects of comprehensive lifestyle modification on diet, weight, physical fitness, and blood pressure control: 18-month results of a randomized trial. Annals of internal medicine. 2006; 144:485-495. [PubMed: 16585662]

Emmons KM, Marcus BH, Linnan L, Rossi JS, Abrams DB. Mechanisms in multiple risk factor interventions: smoking, physical activity, and dietary fat intake among manufacturing workers. Working Well Research Group. Preventive medicine. 1994; 23:481-489. [PubMed: 7971876]

Emmons KM, McBride CM, Puleo E, Pollak KI, Clipp E, Kuntz K, Marcus BH, Napolitano M, Onken J, et al. Project PREVENT: a randomized trial to reduce multiple behavioral risk factors for colon cancer. Cancer epidemiology, biomarkers \& prevention : a publication of the American Association for Cancer Research, cosponsored by the American Society of Preventive Oncology. 2005a; 14:1453-1459.

Emmons KM, Stoddard AM, Fletcher R, Gutheil C, Suarez EG, Lobb R, Weeks J, Bigby JA. Cancer prevention among working class, multiethnic adults: results of the healthy directions-health centers study. American journal of public health. 2005b; 95:1200-1205. [PubMed: 15933240]

Estabrooks PA, Bradshaw M, Dzewaltowski DA, Smith-Ray RL. Determining the impact of Walk Kansas: applying a team-building approach to community physical activity promotion. Annals of behavioral medicine : a publication of the Society of Behavioral Medicine. 2008; 36:1-12. [PubMed: 18607666]

Gillman MW, Pinto BM, Tennstedt S, Glanz K, Marcus B, Friedman RH. Relationships of physical activity with dietary behaviors among adults. Preventive medicine. 2001; 32:295-301. [PubMed: 11277687]

Glasgow RE, Bull SS, Gillette C, Klesges LM, Dzewaltowski DA. Behavior change intervention research in healthcare settings: a review of recent reports with emphasis on external validity. American journal of preventive medicine. 2002; 23:62-69. [PubMed: 12093425]

Glasgow RE, Green LW, Klesges LM, Abrams DB, Fisher EB, Goldstein MG, Hayman LL, Ockene JK, Orleans CT. External validity: we need to do more. Annals of behavioral medicine : a publication of the Society of Behavioral Medicine. 2006; 31:105-108. [PubMed: 16542124] 
Glasgow RE, McKay HG, Piette JD, Reynolds KD. The RE-AIM framework for evaluating interventions: what can it tell us about approaches to chronic illness management? Patient education and counseling. 2001; 44:119-127. [PubMed: 11479052]

Graves N, Barnett AG, Halton KA, Veerman JL, Winkler E, Owen N, Reeves MM, Marshall A, Eakin E. Cost-effectiveness of a telephone-delivered intervention for physical activity and diet. PloS one. 2009; 4:e7135. [PubMed: 19779611]

Greaney ML, Puleo E, Bennet GG, Haines J, Viswanath K, Gillman MW, Sprunck-Harrild K, Coeling M, Rusinak D, et al. Addressing multiple behavioral risk factors in primary care: The Healthy Directions 2 Study. Health Educ Behav. In Press.

Green LW. Public health asks of systems science: to advance our evidence-based practice, can you help us get more practice-based evidence? American journal of public health. 2006; 96:406-409. [PubMed: 16449580]

Green LW. Making research relevant: if it is an evidence-based practice, where's the practice-based evidence? Family practice. 2008; 25(Suppl 1):i20-24. [PubMed: 18794201]

Hardcastle SJ, Taylor AH, Bailey MP, Harley RA, Hagger MS. Effectiveness of a motivational interviewing intervention on weight loss, physical activity and cardiovascular disease risk factors: a randomised controlled trial with a 12-month post-intervention follow-up. The international journal of behavioral nutrition and physical activity. 2013; 10:40. [PubMed: 23537492]

Hung HC, Joshipura KJ, Jiang R, Hu FB, Hunter D, Smith-Warner SA, Colditz GA, Rosner B, Spiegelman D, et al. Fruit and vegetable intake and risk of major chronic disease. Journal of the National Cancer Institute. 2004; 96:1577-1584. [PubMed: 15523086]

Institute of Medicine. Crossing the quality chasm: A new health system for the 21 st Century. National Academy Press; Washington, DC: 2001.

Jeffery RW, Forster JL, French SA, Kelder SH, Lando HA, McGovern PG, Jacobs DR Jr, Baxter JE. The Healthy Worker Project: a work-site intervention for weight control and smoking cessation. American journal of public health. 1993; 83:395-401. [PubMed: 8438979]

Klesges LM, Estabrooks PA, Dzewaltowski DA, Bull SS, Glasgow RE. Beginning with the application in mind: designing and planning health behavior change interventions to enhance dissemination. Annals of behavioral medicine : a publication of the Society of Behavioral Medicine. 2005; 29(Suppl):66-75. [PubMed: 15921491]

Macera CA, Ham SA, Jones DA, Kimsey CD, Ainsworth BE, Neff LJ. Limitations on the use of a single screening question to measure sedentary behavior. American journal of public health. 2001; 91:2010-2012. [PubMed: 11726385]

Marcus BH, Albrecht AE, King TK, Parisi AF, Pinto BM, Roberts M, Niaura RS, Abrams DB. The efficacy of exercise as an aid for smoking cessation in women: a randomized controlled trial. Archives of internal medicine. 1999; 159:1229-1234. [PubMed: 10371231]

McLeroy KR, Bibeau D, Steckler A, Glanz K. An ecological perspective on health promotion programs. Health education quarterly. 1988; 15:351-377. [PubMed: 3068205]

Miller, WR.; Rollnick, S. Motivational Interviewing: Preparing people to change addictive behaviors. Guilford Press; New York: 1991.

Ockene JK, Emmons KM, Mermelstein RJ, Perkins KA, Bonollo DS, Voorhees CC, Hollis JF. Relapse and maintenance issues for smoking cessation. Health psychology : official journal of the Division of Health Psychology, American Psychological Association. 2000; 19:17-31.

Orleans CT. Addressing multiple behavioral health risks in primary care. Broadening the focus of health behavior change research and practice. American journal of preventive medicine. 2004; 27:1-3. [PubMed: 15275668]

Pan A, Sun Q, Bernstein AM, Schulze MB, Manson JE, Stampfer MJ, Willett WC, Hu FB. Red meat consumption and mortality: results from 2 prospective cohort studies. Archives of internal medicine. 2012; 172:555-563. [PubMed: 22412075]

Pirie PL, McBride CM, Hellerstedt W, Jeffery RW, Hatsukami D, Allen S, Lando H. Smoking cessation in women concerned about weight. American journal of public health. 1992; 82:12381243. [PubMed: 1503165] 
Prochaska JJ, Nigg CR, Spring B, Velicer WF, Prochaska JO. The benefits and challenges of multiple health behavior change in research and in practice. Preventive medicine. 2010; 50:26-29. [PubMed: 19948184]

Resnicow K, Jackson A, Blissett D, Wang T, McCarty F, Rahotep S, Periasamy S. Results of the healthy body healthy spirit trial. Health psychology : official journal of the Division of Health Psychology. American Psychological Association. 2005; 24:339-348.

Ritzwoller DP, Sukhanova AS, Glasgow RE, Strycker LA, King DK, Gaglio B, Toobert DJ. Intervention costs and cost-effectiveness for a multiple-risk-factor diabetes self-management trial for Latinas: economic analysis of inverted exclamation mark ¡Viva Bien! Translational behavioral medicine. 2011; 1:427-435. [PubMed: 22081776]

Serdula M, Coates R, Byers T, Mokdad A, Jewell S, Chavez N, Mares-Perlman J, Newcomb P, Ritenbaugh $\mathrm{C}$, et al. Evaluation of a brief telephone questionnaire to estimate fruit and vegetable consumption in diverse study populations. Epidemiology. 1993; 4:455-463. [PubMed: 8399695]

Simons-Morton BG, Parcel GS, Baranowski T, Forthofer R, O'Hara NM. Promoting physical activity and a healthful diet among children: results of a school-based intervention study. American journal of public health. 1991; 81:986-991. [PubMed: 1854016]

Sorensen G, Emmons K, Hunt MK, Barbeau E, Goldman R, Peterson K, Kuntz K, Stoddard A, Berkman L. Model for incorporating social context in health behavior interventions: applications for cancer prevention for working-class, multiethnic populations. Preventive medicine. 2003; 37:188-197. [PubMed: 12914824]

Spring B, Moller AC, Coons MJ. Multiple health behaviours: overview and implications. J Public Health (Oxf). 2012a; 34(Suppl 1):i3-10. [PubMed: 22363028]

Spring B, Schneider K, McFadden HG, Vaughn J, Kozak AT, Smith M, Moller AC, Epstein L, Russell SW, et al. Make Better Choices (MBC): study design of a randomized controlled trial testing optimal technology-supported change in multiple diet and physical activity risk behaviors. BMC public health. 2010; 10:586. [PubMed: 20920275]

Spring B, Schneider K, McFadden HG, Vaughn J, Kozak AT, Smith M, Moller AC, Epstein LH, Demott A, et al. Multiple behavior changes in diet and activity: a randomized controlled trial using mobile technology. Archives of internal medicine. 2012b; 172:789-796. [PubMed: 22636824]

Sukhanova A, Ritzwoller DP, Alexander G, Calvi JH, Carlier C, McClure JB, Rolnick S, Johnson C. Cost analyses of a web-based behavioral intervention to enhance fruit and vegetable consumption. The international journal of behavioral nutrition and physical activity. 2009; 6:92. [PubMed: 20040096]

Tinetti ME, Fried TR, Boyd CM. Designing health care for the most common chronic condition-multimorbidity. JAMA : the journal of the American Medical Association. 2012; 307:2493-2494.

Troost JP, Rafferty AP, Luo Z, Reeves MJ. Temporal and regional trends in the prevalence of healthy lifestyle characteristics: United States, 1994-2007. American journal of public health. 2012; 102:1392-1398. [PubMed: 22095344]

Tunis SR, Stryer DB, Clancy CM. Practical clinical trials: increasing the value of clinical research for decision making in clinical and health policy. JAMA : the journal of the American Medical Association. 2003; 290:1624-1632.

U.S. Department of Agriculture and U.S. Department of Health and Human Services. Dietary guidelines for Americans, 2005. 6. Government Printing Office; Washington DC: 2005.

U.S. Department of Agriculture and U.S. Department of Health and Human Services. Dietary Guidelines for Americans. 7. Vol. 2010. Government Printing Office; Washington DC: 2010.

U.S. Department of Health and Human Services. 2008 Physical activity guidelines for Americans. Washington DC: 2008.

Unger JB. Stages of change of smoking cessation: relationships with other health behaviors. American journal of preventive medicine. 1996; 12:134-138. [PubMed: 8777067]

Warburton, DE.; Nicol, C.; Bredin, S. Guidelines Advisory Committee Report, 2008. Washington DC: 2008. Physical activity guidelines advisory committee.

Warburton DE, Nicol CW, Bredin SS. Health benefits of physical activity: the evidence. CMAJ : Canadian Medical Association journal = journal de l'Association medicale canadienne. 2006; 174:801-809. 
Weiss CO, Boyd CM, Yu Q, Wolff JL, Leff B. Patterns of prevalent major chronic disease among older adults in the United States. JAMA : the journal of the American Medical Association. 2007; 298:1160-1162.

Willett WC, Sampson L, Stampfer MJ, Rosner B, Bain C, Witschi J, Hennekens CH, Speizer FE.

Reproducibility and validity of a semiquantitative food frequency questionnaire. American journal of epidemiology. 1985; 122:51-65. [PubMed: 4014201] 


\section{Highlights}

- A study of a multiple risk behavior intervention in the primary care setting

- Targets fruit/vegetable, red meat, multi-vitamin, physical activity, \& smoking

- Compared self-guided intervention alone and with 2 telephone coaching calls

- Both interventions led to improvements in MRB score over usual care 


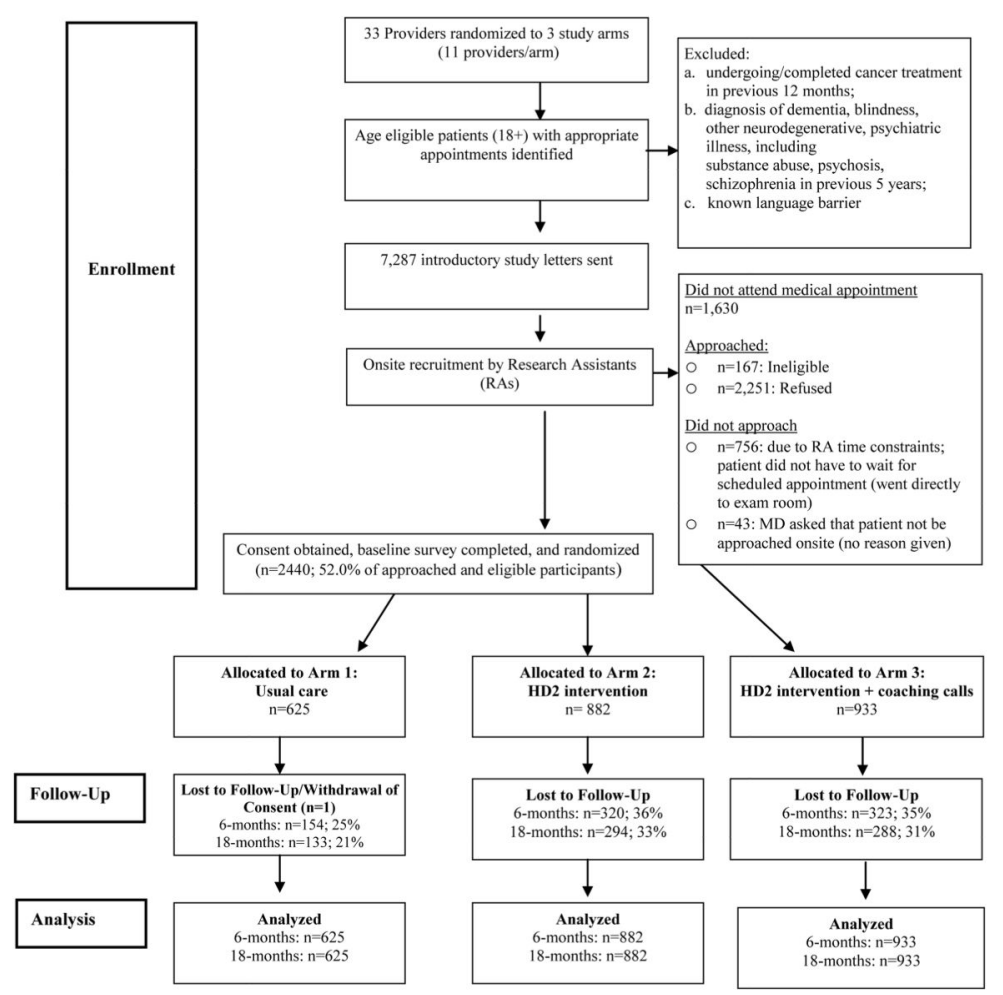

Figure 1.

Healthy Directions 2 Study Design—CONSORT Figure 

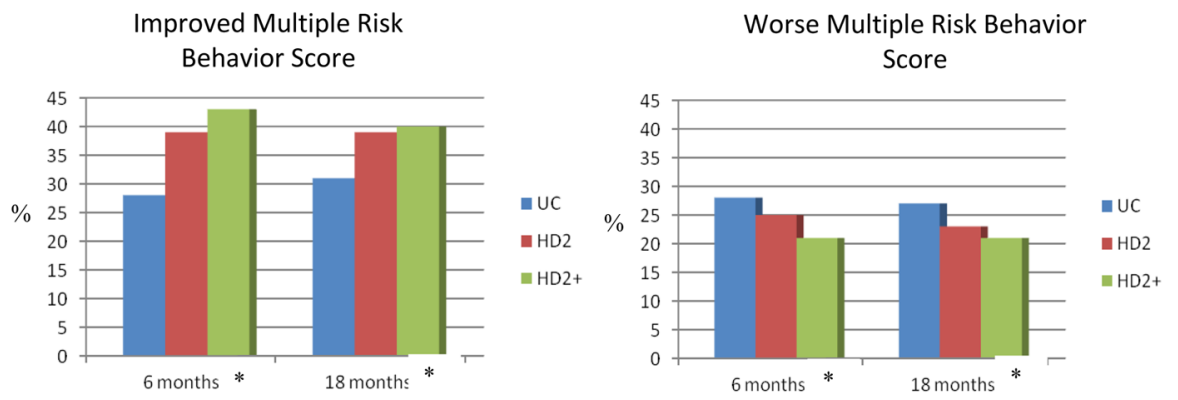

* UC significantly different from $\mathrm{HD} 2$ and $\mathrm{HD} 2+\mathrm{CC}$

Figure 2.

Change in Multiple Risk Behavior Score by Intervention Condition at end of Intervention (6 mos.) and at 18 mos. Post-Baseline, Controlling for Baseline 
Table 1

Baseline Characteristics of 2440 participants in the Healthy Directions 2 Study

\begin{tabular}{|c|c|c|c|c|}
\hline & Total & Usual Care & HD2 & HD2+ \\
\hline$\underline{\text { Sociodemographics }}$ & Mean (SE) & Mean (SE) & Mean (SE) & Mean (SE) \\
\hline \multirow[t]{2}{*}{ Age (years) ${ }^{*}$} & $49.0(\mathrm{SE}=1.10)$ & $46.7(1.76)$ & $51.5(1.95)$ & $48.8(1.71)$ \\
\hline & $\underline{\mathrm{N}(\%)}$ & $\underline{\mathrm{N}(\%)}$ & $\underline{\mathrm{N}(\%)}$ & $\underline{\mathrm{N}(\%)}$ \\
\hline Female $^{*}$ & $1604(65.8 \%)$ & $499(79.4)$ & $510(56.6)$ & 595 (61.9) \\
\hline \multicolumn{5}{|l|}{ Race/ethnicity } \\
\hline White & $1307(55.0)$ & $344(56.4)$ & $458(52.7)$ & $505(55.8)$ \\
\hline Black & $667(27.6)$ & $165(26.1)$ & $265(31.2)$ & $237(25.4)$ \\
\hline Hispanic/Latino & $215(9.0)$ & $53(8.6)$ & $67(7.8)$ & $95(10.5$ \\
\hline Other (includes multiracial, Asian) & $201(8.5)$ & $55(8.9)$ & $71(8.3)$ & $75(8.3)$ \\
\hline \multicolumn{5}{|l|}{ Education } \\
\hline$\leq$ High school/GED & $385(16.0)$ & $99(16.0)$ & $150(17.3)$ & $136(14.6)$ \\
\hline Some college/technical training/2 year degree & $577(23.9)$ & $146(23.0)$ & $220(25.7)$ & $211(23.1)$ \\
\hline$\geq$ College degree & $1441(60.0)$ & $374(61.0)$ & $494(57.0)$ & $573(62.2)$ \\
\hline Married or living with a partner & $1512(62.7)$ & $370(60.0)$ & $538(62.1)$ & $604(66.0)$ \\
\hline \multicolumn{5}{|l|}{ Household's financial status } \\
\hline Cannot make ends meet & $125(5.3)$ & $33(5.5)$ & $55(6.4)$ & $37(4.0)$ \\
\hline Have to cut back & $476(20.0)$ & $125(20.3)$ & $167(19.5)$ & $184(20.0)$ \\
\hline Enough, no extras & $683(29.3)$ & $188(30.9)$ & $239(28.3)$ & $256(28.6)$ \\
\hline Comfortable with some extras & $1083(45.5)$ & $261(43.2)$ & $389(45.7)$ & $433(47.4)$ \\
\hline \multicolumn{5}{|l|}{ Multiple risk behavior (MRB) score } \\
\hline 0 (met all 5 recommendations) & $99(4.0)$ & $24(3.7)$ & $37(4.3)$ & $38(4.0)$ \\
\hline 1 (met 4 recommendations) & $419(17.3)$ & $103(16.9)$ & $156(17.7)$ & $160(17.1)$ \\
\hline 2 (met 3 recommendations) & $744(31.3)$ & $199(32.7)$ & $266(31.3)$ & $279(30.1)$ \\
\hline 3 (met 2 recommendations) & $771(32.6)$ & $200(33.0)$ & $263(30.5)$ & $308(34.3)$ \\
\hline 4 (met 1 recommendations) & $313(13.0)$ & $71(11.5)$ & $123(14.4)$ & $119(13.1)$ \\
\hline 5 (met none of the recommendations) & $41(1.8)$ & $13(2.1)$ & $16(1.9)$ & $12(1.3)$ \\
\hline
\end{tabular}

